\title{
Orbital Index in Urhobos of Nigeria
}

\author{
Ebeye O.A, Otikpo O. \\ Department Of Anatomy, Delta State University Abraka, Nigeria
}

\begin{abstract}
The orbit is the cavity or socket of the skull in which the eye and its appendages are situated. Normal values of orbital height, orbital width and orbital index are vital measurements in evaluation and diagnosis of craniofacial syndromes and post traumatic deformities, treatment of abnormalities to produce the best aesthetic and functional result is important. Thus the study was conducted to document normal orbital values in a Nigeria population. Two hundred and thirty six males and one hundred and fifty two female volunteer adult Urhobos were selected randomly among the student of Delta State University Abraka age ranged 18-30years. There orbital height and orbital width were measured and the orbital index calculated (OI/OWX 100). Result showed mean orbital height and width were higher in males $(33.01 \mathrm{~mm}$ and $42.24 \mathrm{~mm})$ than in females $(31.92 \mathrm{~mm}$ and $40.82 \mathrm{~mm})$. This was statistically significant $(p<0.05)$. The study showed sexual dimorphism and places the population in microseme (small) category. This study will be of importance in anthropology, forensic medicine and craniofacial surgery.
\end{abstract}

Key Words: orbit, orbital height, orbital width, urhobos

Submitted Date 20 Apr 2013

Accepted Date: 25 Apr 2013

\section{Introduction}

The orbit is the cavity or socket of the skull in which the eye and its appendages are situated. Orbit can be referred to as the bony socket, ${ }^{[1]}$ or it can also be used to imply the contents. ${ }^{[2]}$ In the adult human, the volume of the orbit is $30 \mathrm{ml}$, of which the eye occupies $6.5 \mathrm{ml} .{ }^{[3]}$ The orbits are conical or four-sided pyramidal cavities, which open into the midline of the face and point back into the head. Each consists of a base, an apex and four walls. They protect the eye from mechanical injury. Each orbital cavity measures about $40 \mathrm{~mm}$ with the width usually greater than the height the relationship between the two is given by orbital index which varies in different races of mankind. Understanding its structure proportion and mechanical function is vital in ophthalmology, oral maxillofacial surgery and neurosurgery. Anthropology aids the understanding of anatomic structures and constitutes the technique of expressing quantitatively the form of human body and skeleton (4) for these reasons standards based on ethnic or racial data are desirable because the standards reflects the potentially different patterns of craniofacial growth resulting from racial ethnic and sexual differences.

Orbital indices have been studied by several authors. Suzuki 1969 reported microseme type of eye in East Asia, Adebisi 2003, evaluated sexual dimorphic characteristics in Hausa and Fulani he observed low dimensions in males than females. Gabriel et al., 2009 studied The Circumference Interorbital Index of Ijaw and Igbo Ethnic Groups in Nigeria. Igbigbi and Ebite in 2010 calculated orbital index in Malawians. Ukoha et al., 2011 studied Orbital dimensions of adult male Nigerians: a direct measurement study using dry Skulls,

These studies indicate racial and ethnic differences occur in orbital index amongst different population. The present study was aimed at documenting standard values of orbital indices in a Nigerian ethnic group and comparing it with available data from other populations of the world. These would be very useful in anthropological studies, craniofacial surgery, diagnosis of craniofacial anomalies and forensic medicine.

\section{Materials And Methods}

Three hundred and eighty-eight volunteer Urhobo subjects were selected randomly. The ages of the subject ranged from $18-30$ years. All the subjects used for this study had normal craniofacial configuration. Subjects with any craniofacial abnormality or prior craniofacial surgery were excluded.

PROCEDURE: Measurements were taken at fixed time between 9am and 1pm to eliminate the discrepancies due to diurnal variation. Standard methods were used for all measurements ${ }^{(9,10)}$.subjects sat upright on a chair, the examiner also sat on a chair opposite the subject head at same level as the examiner head. All measurements were taken twice and average reading recorded.

- ORBITAL HEIGHT: this refers to the distance between the superior and inferior margin of the orbital fossa.

- ORBITAL WIDTH: the distance between the medial and lateral walls of the orbital fossa (from the frontal process of the zygomatic arch to the frontal process of the maxilla. 


\section{- ORBITAL INDEX: ORBITAL HEIGHT/ORBITAL WIDTH X 100}

Orbital index are classified as follows.

- Megaseme (large) - The orbital index is 89 or over. This type is characteristics of the yellow races, except the Esquimaux (Eskimos) where the orbital opening is round. ${ }^{11}$,

- Mesoseme (intermediate) - The orbital index range between 89 and 83. This type is found in the white races (European 87, English 88.4). ${ }^{12}$

- Microseme (small) - Orbital index 83 or less. This type is characteristics of the black races where the orbital opening is rectangular. ${ }^{13}$

\section{Results}

The results of this study are presented in the table below

Table 1: summary of orbital indices

$\begin{array}{lllll} & \text { MALES } & & \text { FEMALES } \\ & \text { MEANS } & \text { SD } & \text { MEANS } & \text { SD } \\ \text { ORBITAL HEIGHT } & 33.01(\mathrm{~mm}) & 3.22 & 31.92(\mathrm{~mm}) & 3.07 \\ \text { ORBITAL WIDTH } & 42.24(\mathrm{~mm}) & 2.64 & 40.82(\mathrm{~mm}) & 3.29 \\ \text { ORBITAL INDEX } & 78.15 & 0.82 & 78.57 & 0.6 \\ \text { SAMPLE SIZE } & 236 & & 152 & \end{array}$

Table 1 shows the mean orbital height in males is $33.01 \mathrm{~mm}$ while in females its $31.92 \mathrm{~mm}$, orbital width in males was found to be $42.24 \mathrm{~mm}$ and 40.82 in females, also orbital index was found to be 78.15 in males and 78.57 in females. All the indices above are found to be higher in males than females. The difference between males and females indices were statistically significant $(\mathrm{p}<0.05)$.

\section{Discussion}

From this study, the mean orbital index of adult Urhobo male was found to be $78.15 \pm 0.82$ and adult Urhobo females $78.99 \pm 0.38$. This value places the orbital index of adult Urhobo males and females in Micoseme category (small orbital index of less than 83). This confirms a previous study which demonstrated that the black races have microseme orbital index. The study of orbital index in adult Malawians by Igbigbi and Ebite in 2010 differ from this study as it places the Malawian orbit in the megaseme category, also the study of Ukoha et al., 2011 also differ from this study as it agrees with Igbigbi and Ebite. These differences seen in these black populations may be attributed to magnification factor of x-ray machines. The difference may also be attributed to mode of measurement; all the other studies took their measurements on x-rays while in this study direct measurements technique has been employed in assessing bony orbit within our environment. Anthropometric studies are an integral part of biological variability 14, 15, forensic investigation 16, 17, 18, craniofacial surgery and syndromology ${ }^{19}$. Normal values of orbital indices are vital measurements in the evaluation, and diagnosis of craniofacial syndromes and post traumatic deformities, and knowledge of the normal values for a particular region can be used to treat abnormalities to produce the best aesthetics and functional result ${ }^{10}$. For these purposes, standards based on local data are desirable, since these standards reflect the different patterns of craniofacial growth resulting from racial, ethnic, social and dietary differences.

\section{Conclusion}

This study provides useful baseline anthropometric data that will be of clinical and surgical interest in ophthalmology, oral and maxillofacial surgery and indeed neurosurgery in this part of the world. We recommend that anthropologists, clinicians and forensic experts should obtain this data and used in their quest for knowledge. We also recommend that more studies covering most tribes and ethnic groups in Nigeria be carried out for comprehensive documentation.

\section{References}

[1]. Moore, Keith L. (2010). Clinically Oriented Anatomy 6th Ed. Lippincott Williams \& Wilkins.

[2]. Duane's Ophthalmology, Chapter 32 Embryology and Anatomy of the Orbit and Lacrimal System. (eds Tasman W, Jaeger EA) Lippincott/Williams \& Wilkins, 2007

[3]. "eye, human."Encyclopædia Britannica from Encyclopædia Britannica 2006 Ultimate Reference Suite DVD 20095009

[4]. Ukoha U., Egwu O.A., Okafor I.J., Ogugua P.C., Onwudinjo O., Udemezue O.O. (2011). Orbital dimensions of adult male Nigerias: a direct measurement study using dry skulls. International Journal of Biological and Medical Research.

[5]. Suzuki H. (1969). Micro evolutional changes in the Japanese population from prehistoric age to the present day. Journal of faculty of science, university of Tokyo, japan. 2(3): 279-308

[6]. Adebisi S.S. (2003). Sex identification from the skull of the Hausa/Fulani in northern Nigeria. Annals of African medicine. 
[7]. Oladipo G.S., Ugboma A., Oyakhire M.O. (2009). The Circumference Interorbital Index of Ijaw and Igbo Ethnic Groups in Nigeria. The Internet Journal of Biological Anthropology. Volume 3 Number 2.

[8]. Igbigbi P.S., Ebite, L.E. (2010) Orbital Index of Adult Malawians. Anil Aggrawal's Internet Journal of Forensic Medicine and Toxicology. Vol. 11, No. 1

[9]. Evereklioglu C., Cengiz Y., Hamdi E., Selim D and Yasar D. (2001). Normative values of craniofacial measurements in idiopathic benign macrocephalic children. The cleft palate craniofacial Journal. 38 (3) :260-263.

[10]. Evereklioglu C., Dogany S., Er H., Gunduz A., Tercan M., Balat A. (2002). Craniofacial anthropometry in a Turkish population. Cleft palate craniofacial J 39(2): 208-218.

[11]. Patrick. J. megaseme" webster 1913 dictionary. Cassidy 1913 answers.com (homepage on the internet) available from http://www.answers.com/topic/megaseme.

[12]. "mesoconch" Mcgraw hill dictionary of scientific and technical terms, Mcgraw hill company inc, 2003 answers .com(homepage on the internet) available from http://www.answers.com/topic/mesoconch

[13]. Patrick. J. Cassidy. (1913) "microseme" webster 1913 dictionary. answers.com (homepage on the internet) available from http://www.answers.com/topic/microseme

[14]. Krishan K. Determination of stature from foot and its segments in a North Indian population. American Journal of Forensic Medicine and Pathology; 2008, 29(4):297-303.

[15]. Krishan K. Estimation of stature from footprint and foot outline dimensions in Gujjars of North India. Forensic Science International. 2008; 175(2-3):93-101.

[16]. Krishan K. Establishing correlation of footprints with body weight--forensic aspects. Forensic Science International 2008; 179(1):63-96.

[17]. Krishan K, Sharma A. Estimation of stature from dimensions of hands and feet in a North Indian population. Journal of Forensic and Legal Medicine 2007; 14(6):327-332.

[18]. Krishan K. Anthropometry in Forensic Medicine and Forensic Science-'Forensic Anthropometry'. The Internet Journal of Forensic Science, 2007; 2 (1).

[19]. Farkas L. G, Posnick J. C, Hreezko T. M, Pron G. E. Anthropometric growth study of the head. Cleft Palate Craniofac. J.1992, 29:303-308 